Revista Multidisciplinar do Nordeste Mineiro, v.2 2019/02

ISSN 2178-6925

\title{
INCLUSÃO DE ALUNOS COM SÍNDROME DE NOONAN E DEMAIS SÍNDROMES: PROFESSORES PREPARADOS?
}

\section{INCLUSION OF STUDENTS WITH NOONAN SYNDROME AND OTHER SYNDROMES: PREPARED TEACHERS?}

\author{
Rosemeire Aparecida Leal Bologenzi \\ Mestre em Educação, pela Pontifícia Universidade Católica do Paraná-PUCPR, \\ Curitiba. PR, Brasil. \\ Email: rosemeire.bolognezi@gmail.com
}

\section{Resumo}

Este artigo tem como objetivo observar como se acontece a inclusão um aluno co Síndrome de Noonan no ensino fundamental anos finais da rede pública de ensino do estado do Paraná, as contribuições e dificuldades que alunos com esta síndrome pode passar como ser atuante da educação básica no Brasil. Atualmente vivencia-se um momento muito importante para a educação inclusiva, onde o direito a se ter uma educação igualitária é fundamental para o aluno com deficiência e esta assegurado na legislação, independente de suas necessidades todo aluno ter 0 direito em estar matriculado numa escola de ensino regular. Entretanto, para se efetivar a educação inclusiva é necessário que a comunidade escolar se adeque às necessidades e individualidades do aluno, buscando oferecer condições efetivas de aprendizagem e desenvolvimento de suas potencialidades.

Palavras-chave: Síndrome de Noonan, Inclusão, Educação.

\section{Abstract}

This article aims to observe how the inclusion of a student with Noonan Syndrome happens in the elementary school final years of the public school system of the state of Paraná, the contributions and difficulties that students with this syndrome can pass as being active in basic education in the state. Brazil. Nowadays there is a very important moment for inclusive education, where the right to have an equal education is fundamental for the student with disabilities and it is ensured in the legislation, regardless of their needs every student has the right to be enrolled in a school. regular education. However, in order to achieve inclusive education, the school community needs to adapt to the student's needs and individualities, seeking to offer effective learning conditions and the development of their potential.

Keywords: Noonan Syndrome, Inclusion, Education.

\section{Introdução}

A Síndrome de Noonan (SN) é uma síndrome que acomete bem mais pessoas do que o conhecimento que se tem sobre ela. A SN é uma doença de herança autossômica, cuja incidência de casos estima-se um para cada 1000 - 2500 
nascidos vivos, identificado por Nora (1974), desta forma, percebe-se que a incidência de nascidos com esta síndrome é grande, mesmo não sendo da ciência de muitos, tal síndrome chega a se equivaler em números a síndrome de Down, que estima ser de 1 - 700 nascimentos, como afirma Medina (2018).

Pessoas com SN apresentam características faciais específicas, problemas relacionados ao crescimento, alterações esqueléticas, linfáticas e cardíacas, sobretudo, podem apresentar déficit cognitivo, segundo vários pesquisadores como Mendez et al. (1985), Sharland et al. (1992), Tartaglia et al. (2001), e no Brasil, esses estudos são feitos por Bertola (1999); Malaquias (2008); Brasil (2009), Padovani (2011) entre outros, todos estudos no campo da medicina.

Esta síndrome era confundida inicialmente com a síndrome de Turner, a síndrome de Costello sendo difícil diagnóstico, por serem similares em suas características, mas somente em 1963 Noonan e Ehmke realizaram estudos com nove pacientes (três do sexo feminino) e identificaram que os pacientes apresentavam estenose valvar pulmonar associada à baixa estatura, dismorfismo facial e retardo mental moderado, tais descrições que a distinguia das demais síndromes (NOONAN ; EHMKE, 1963), após estes estudos passou-se a identificála como Síndrome de Noonan sugestão dada por Optiz, em 1965. (OPTIZ, 1965).

Após Declaração de Salamanca (1994) e a implantação do Estatuto do Deficiente (2015) é que crianças também com SN tiveram a oportunidade de frequentar a rede regular de ensino, sendo assim um momento muito importante para a educação inclusiva, de alunos com necessidades educacionais especiais, porém isso não basta, é importante ressaltar que este acolhimento é fundamental, mas o aluno com necessidades educacionais especiais necessita de condições efetivas de aprendizagem e desenvolvimento de suas potencialidades. Desta forma, é necessário e urgente, que os sistemas de ensino além de assegurar essas matrículas, ofereçam também condições condizentes para a aprendizagem destes alunos, sobretudo na preparação das pessoas que diretamente estarão responsáveis pela aprendizagem destes alunos.

\section{Reflexos de alunos com Sindrome de Noonan no ensino regular}

\subsection{Definição Sindrome de Noonan}

O estudo sobre a Síndrome de Noonan (SN), historicamente teve início com 
kobylinski (1883), seguida de Noonan e Ehmke (1963), no qual analisaram um grupo de crianças que apresentavam características que se evidencia hoje como a Síndrome de Noonan, em referência a Dra. Jacqueline Noonan, primeira profissional, cardiologista pediátrica a identificar a síndrome.

Apesar de ser uma síndrome nova para a educação, já se tem casos de indivíduo com $\mathrm{SN}$, nas escolas regulares, onde os professores anseiam por respostas para estratégias de ensino que possam colaborar com este sujeito no período de sua escolarização, favorecendo condições de se sentirem pertencentes oportunizando sua contribuição no ambiente escolar. (DRAGO; PINEL, 2014).

Vivenciando o momento de querer entender como ocorrem os processos de inclusão do aluno com deficiência intelectual causada pela SN, no contexto da sala de aula na escola comum, estudos apontam que a inclusão se faz necessária, porém que todo integrante tenha condições de se apropriar a sua maneira e tempo dos conteúdos curriculares, que as instituições precisam dar atendimento a esses alunos, respeitando seus limites e conduzindo para uma ampliação de seus conhecimentos, assim como aborda Mantoan (2003).

Mas, muitas lacunas perduram entre estar inserido a uma escola regular e sentir-se atuante nela, não tem-se promovido o devido ensino aos alunos de inclusão, devido as próprias políticas públicas, e o trabalho de alguns educadores como menciona Briant e Olivier (2012),

Na prática, encontramos ainda professores despreparados para essa realidade e com falta de uma rede de apoio para desenvolver o seu trabalho com qualidade. Essa rede de apoio voltada para a construção de possibilidades de inclusão de crianças com deficiências na escola pode envolver além de diferentes profissionais do campo da educação, profissionais da área da saúde, como o terapeutas ocupacional, por meio do trabalho de apoio direto ou indireto ao professor, à família, à comunidade escolar e também à criança. (BRIANT; OLIVIER, 2012).

Infelizmente observa-se que as diferenças e a não inclusão ainda existem ou uma aparente inclusão como menciona Zuffi (2014), quando questiona ação do professor que deve por finalidade pesquisar planos e estratégias, para avaliar os alunos com necessidades especiais, verificar o grau de dificuldade de cada um em sala de aula, descobrir as habilidades e potencialidades que precisam ser exploradas e modificá-las, se o mesmo não criar condições, buscar recursos que favoreçam a participação e o aprendizado dos alunos, este ficará "esquecido", ali, 
bem à sua frente, sem ter nada para fazer. Ou então, se este profissional recorrer a atividades que não contemplam o conteúdo curricular como, por exemplo, atividades de pintura ou desenho, que nada fará compreender para este aluno, o sentido de fazer parte de uma disciplina específica, só pelo fato de fazer parte de uma inclusão educacional, de nada adiantou, todas as lutas, leis, estudos, formações, a que refletir sobre o papel da inclusão da forma como se encontra hoje nas escolas.

Para tanto o plano de trabalho docente do professor deve ser flexível para que atenda e se adapte a demanda das necessidades que se encontra em sala de aula, que em números é crescente os diversos tipos de inclusão e o professor deve estar preparado a todas essas, Paraná (2014).

Para Vigotski (1997) em seus estudos sobre defectologia, o mesmo traz entendimentos sobre a deficiência intelectual, afirmando que existem padrões únicos de análises de desenvolvimento para as pessoas "normais" e para as com deficiência. Segundo o autor,

a moderna investigação científica, que estuda comparativamente os problemas de desenvolvimento de criança normal e anormal, parte de uma tese geral: as leis que regem o desenvolvimento tanto da criança normal como da anormal, são essencialmente as mesmas, assim como as leis que governam a atividade vital seguem sendo as mesmas se são normais ou patológicas as condições de funcionamento de qualquer órgão ou do organismo em seu conjunto (VIGOTSKI, 1997, p. 45).

Se as leis são as mesmas não há inclusão, se os alunos com SN possuem dificuldade de aprendizagem, portanto não desenvolvem com a mesma potencialidade as atividades designada ao demais alunos e assim se faz necessário adaptações para um melhor entendimento, como mencionado por Bertola (2006) e Padavoni (2011).

Ao ser questionado as limitações de alunos com deficiência sobre a aprendizagem, que se justifica a inserção e a permanência destes como parte atuante na construção do saber, Vigotski, (1997) menciona que as diferenças entre as pessoas estão na forma como são vista, entendidas e inseridas na sociedade, o autor defende a não segregação dos alunos com necessidades especiais, pois ao estar inserido em grupos heterogêneos, isto propicia condições para o desenvolvimento do pensamento e da linguagem.

Alunos com deficiência intelectual, tem sim limitações de absorver todo 0 ensinamento, porém privá-lo seria demasiadamente indevido, como também afirma 
(OLIVEIRA; LEITE, 2007), mas se este aluno tem a possibilidade de estar em uma escola regular, é necessário que o olhar do professor esteja voltado para entender que o aluno não se apropria da mesma forma que as outras crianças, e que sim, lhe seja dado condições para realizar atividades em outros níveis, mas dentro do contexto de estudo, mas muitas vezes não é isso que ocorre, e o professor por não ter formação adequada, tempo suficiente para preparação de material, e a sala com inumeras adversidades, o que torna o trabalho inviável ou dificulta o atendimento com qualidade.

O que pode ser corroborado por Mendes (2016), quando menciona sobre as instituições escolares e a atuação do professor diante realidade da inclusão. "Em muitas escolas, ainda, os alunos-alvo da educação especial vão para a sala de aula apenas para socializar-se. Dependendo do caso, eles passam quatro horas sem desempenhar qualquer atividade. Isso é inclusão?" (apud KUZUYABU, 2016, p. 32-37).

Glat (2009) também questiona o fazer no ambiente escolar, a autora comenta que as pessoas com deficiência intelectual teriam uma produção maior se todos que estão envolvidos no ambiente escolar tivessem dado credibilidade e acreditado nas potencialidades do aluno com qualquer deficiência. Infelizmente, nos espaços educacionais, muitas barreiras têm sido impostas a eles.

Quanto a pessoas com SN, não há literatura que se aprofunde nos estudos sobre as características cognitivas desses indivíduos, como menciona Mota et al (2010), a autora destaca que os trabalhos publicados se referem a discutir sobre a formação genética, e clínica dos indivíduos e não encontrando estudos principalmente no Brasil sobre o perfil cognitivo, o que corresponde também aos relatos dos estudos de Bertola (2006) e Padavoni (2011), as autoras destacam também que indivíduos com SN apresentam níveis de cognição 10\% menor do que comparado aos seus familiares, que a idade mental não corresponde as funções que conseguem estabelecer, tendo assim dificuldade de aprendizagem, comprometimento na coordenação motora e na fala.

Com base nessas afirmações, há grandes questionamentos sobre a permanência de alunos de inclusão no ensino regular feitos por professores atuantes, mesmo sabendo-se que é necessário a permanência deste aluno no ensino regular, fica a indagação, como trabalhar com uma síndrome nova que não se encontra respaldo na literatura, nem estudos foram realizados com alunos desta síndrome de Noonan? Mas, ela existe e esta presente na salas de aula. Como fazer 
uma inclusão de algo que não se conhece?

A que se refletir, investir mais especificamente nos estudos sobre as síndromes, suas particularidades, para se repensar na preparação e formação de toda a comunidade escolar para acolher este aluno, que seja oportunizado aos professores suporte para capacita-los e assim possam ter subsídios para desempenharem melhor habilidade profissional atendendo a todos os alunos seja os de inclusão ou não, para que este aluno sinta acolhido por todos e se veja parte atuante do segmento educacional. Maciel (2000).

\subsection{A implementação da educação inclusiva na sala de aula comum}

No Brasil, a educação inclusiva teve uma ampla aceitação a partir da Conferência Mundial de Educação Especial em 1994, quando foi proclamada a Declaração de Salamanca, que normatiza sobre a igualdade de oportunidades para as pessoas com deficiência, passando a ser aceitos os alunos nos ambientes escolares no ensino regular.

A garantia e formulação das políticas públicas tornaram-se necessário o que proporcionou através desta conferência, reunindo noventa e dois países e vinte e cinco organizações internacionais, em Salamanca, na Espanha, sendo proferida a Declaração de Salamanca que visava oportunizar a educação para todos e reconhecer "[...] a necessidade e a urgência de garantir a educação para as crianças, jovem e adulta com necessidades educativas especiais no quadro do sistema regular de educação" (DECLARAÇÃO DE SALAMANCA, 1994, viii). Ficou firmado nesta declaração o compromisso com a educação inclusiva no qual governantes seguiriam as propostas pelo texto recomendado. A Declaração de Salamanca é um marco fundamental na educação inclusiva mundial, referencia na luta e permanência do aluno assegurando o direito, e respeitando suas diferenças individuais, na rede pública de ensino, possibilitando que todos tenham a mesma educação e de qualidade.

Mas, a educação inclusiva, ainda é um desafio a ser entendido na atualidade pela comunidade escolar. Embora, para que tenha efetiva qualidade necessita de que a escola promulgue além da aceitação, também a valorização das diferenças, e as particularidades de cada indivíduo, através das mudanças de paradigmas e na ampliação do Currículo e do Projeto Político Pedagógico, apoiando os professores no processo de ensino e aprendizagem, como sugere Siqueira (2015). 
Assim, quando a educação dispuser de professores respaldados pela formação continuada, isto possibilitará fortes alicerces de uma educação inclusiva, preparando-os para lidarem com o novo, onde as diferenças e o incomum somente se fará valer quando o indivíduo for atuante, possibilitando o repensar, o refazer a ação educativa para efetivar uma educação de qualidade e igualitária. São esses elementos que permite concordar com (JESUS; EFFGEN, 2012), no tocante a investir na formação inicial e continuada do educador.

Em consonância com esses fatos se observa o crescente aumento anual de matrículas de alunos de inclusão na rede regular de ensino pública do estado do Paraná, a partir do ano 2002, são dados fornecidos pela Secretaria de Educação do Paraná, que teve o propósito em criar "o primeiro Concurso Público para Professores da Educação Especial” (PARANÁ, 2010, p. 7), o qual possibilitou a ampliação da oferta de apoios especializados no contexto da escola regular o que contribuiu para o aumento de vagas de alunos especiais nas escolas públicas a partir desta data, no quadro 1 pode-se perceber também que desde a data de 2002, houve algumas oscilações, mas sempre havendo um crescente aumento de matrículas de alunos especiais:

QUADRO 1: Número de Matrículas Anual de Alunos com necessidades especiais no ensino regular no estado do Paraná

\begin{tabular}{|c|c|c|c|c|c|c|c|c|c|c|c|c|c|c|c|c|}
\hline & \multicolumn{16}{|c|}{ ATENDIMENTO EDUCACIONAL ESPECIALIZADO - AEE } \\
\hline $\begin{array}{c}\text { DEPENOENCCA } \\
\text { AOWINISTRATNA }\end{array}$ & 2002 & 2.003 & 2.004 & 2.005 & 2006 & 2.007 & 2008 & 2.009 & 2010 & 2.011 & 2012 & 2.013 & 2014 & 2.015 & 2016 & 2.017 \\
\hline Bandial & 1.123 & 1.540 & 2.059 & 2.957 & 9.225 & 3.866 & 4.511 & 4.203 & 5.270 & 6.903 & 8790 & 10.025 & 10.454 & 10.720 & 11848 & 13.053 \\
\hline Feoderal & 0 & 0 & 0 & 0 & 0 & 0 & 0 & 0 & 0 & 0 & 0 & 0 & 0 & 0 & 0 & 2 \\
\hline Muritipal & 5.660 & 7.660 & 9.112 & 9.830 & 8.825 & 8.359 & 7.511 & 6.941 & 8.502 & 9.397 & 10.450 & 11.012 & 10.348 & 10.682 & 11.110 & 11.878 \\
\hline Privoso & 13 & 46 & 285 & 429 & 492 & 247 & 657 & 1.525 & 1687 & 1.922 & 238 & 18.338 & 2533 & 2001 & 2365 & 2428 \\
\hline To:al & 6,796 & 9.246 & 11.457 & 13.216 & 18,542 & 13.072 & 12,689 & 12,669 & 15.59 & 18.2222 & 21.632 & 39.375 & 23,335 & 23,403 & 25.323 & 27,361 \\
\hline
\end{tabular}

Fonte: ${ }^{1}$ SEED/SUE/DIRPE/CIE-Disseminação de Informações Educacionais

Estas informações foram retiradas do Censo Escolar da Educação Básica com base nas matrículas inciais do estado do Paraná entre os anos de 2002-2017.

O Censo Escolar é um importante levantamento estatístico-educacional de âmbito nacional realizado, anualmente, pelo Instituto Nacional de Estudos e Pesquisas Educacionais Anísio Teixeira (INEP).

\section{1}

Disponível em:

http://www.gestaoescolar.diaadia.pr.gov.br/arquivos/File/censo/serie historica matricula inicial2000 2 017. Acesso em 31/05/2018. 
Observa-se que em todas as instituições de ensino, mesmo com algumas oscilações, mas em sua maioria houveram aumento em todas os anos, isso nos demonstra a aceitação de toda a sociedade da pessoa com necessidade especiais.

Em contrapartida nas escolas de educação especial das redes públicas estadual e municipal houve quedas no número de matrículas, ganhando assim espaço as redes regulares o atendimento dos alunos de inclusão, já na rede privada ocorreram quedas acompanhadas de oscilações, como observado no quadro 2 :

QUADRO 2: Número de Matrículas Anual de Alunos com necessidades especiais no ensino especializado no estado do Paraná

\begin{tabular}{|c|c|c|c|c|c|c|c|c|c|c|c|c|c|c|c|c|}
\hline $\begin{array}{l}\text { OCPCNOENCLA } \\
\text { ADM NISTRATINA }\end{array}$ & 2,002 & 2003 & 2.004 & 2.005 & 2.006 & 2.007 & 2008 & 2.009 & 2010 & 2.011 & 2.012 & 2.013 & 2014 & 2.015 & 2.016 & 2.017 \\
\hline cotedual & 1.200 & 1.135 & 1.263 & 1.102 & 822 & 478 & 497 & 763 & 433 & 332 & 139 & 327 & 312 & 209 & 364 & 334 \\
\hline rederel & 0 & 0 & 0 & 0 & 0 & 0 & 0 & 0 & 0 & 0 & 0 & 0 & 0 & 0 & 0 & 0 \\
\hline Muriogs & 10.752 & 11.570 & 12.119 & 12.068 & 12.261 & 12.222 & 13.138 & 10.925 & 9.595 & 7.778 & 7.072 & 6.998 & 6.601 & 6.670 & 6.916 & 7.278 \\
\hline Prinds & 32.257 & $33.9 \%$ & 35.909 & 36.796 & 38.122 & 35.647 & 21.291 & 17.612 & 16.512 & 16.230 & 32.459 & 33.311 & 33.252 & 32.555 & 32.625 & 32.937 \\
\hline Total & 44.299 & 46,681 & 49.291 & 50,766 & 51.205 & 49,347 & 34,926 & 29.300 & 26,540 & 24,340 & 39,670 & 40,636 & 40,165 & 39,434 & 39,905 & 40,549 \\
\hline
\end{tabular}

Fonte: ${ }^{2}$ SEED/SUE/DIRPE/CIE-Disseminação de Informações Educacionais

Segundo Mantoan (2013), tais mudanças deve-se a implementação das Políticas públicas, leis e conscientização da população, em contrapartida as escolas exclusivas para pessoas com deficiência cada vez mais perdem seu espaço.

Ao mencionar que a comunidade escolar deve refletir e repensar ações para promover alterações que consideram oportunas a toda a comunidade escolar para 0 bem comum do aluno, que juntos possam oferecer respaldo curricular, metodológico, pedagógico, avaliativo e outras práticas que se façam necessárias neste processo inclusivo (FERREIRA, 2016), mas o que se observa é que as escolas não estão conseguindo obter estruturas para este fim, observa-se professores despreparados ou com pouca formação específica e continuada, passando a contar com o auxílio do professor de atendimento especializado, isso quando o aluno tem direito, no estado do Paraná somente esta direcionado um professor auxiliar quando o aluno possuir algumas das especifidades relacionado no Anexo VII - Organização do trabalho pedagógico especializado na rede pública estadual de ensino abaixo:

Professor de Apoio Educacional Especializado - (PAEE), para o aluno com Transtorno Global do Desenvolvimento TGD; Professor de

$$
2
$$

Disponível em:

http://www.gestaoescolar.diaadia.pr.gov.br/arquivos/File/censo/serie historica matricula inicial2000 2 017. Acesso em 31/05/2018. 
Apoio à Comunicação Alternativa - (PAC) - Deficiência Física Neuromotora - DFN; Tradutor e Intérprete de Língua Brasileira de Sinais /Língua Portuguesa - (TILS) Surdez; Professor de Libras e/ou instrutor surdo; Guia Intérprete - Surdocego; Professor itinerante Cego (PARANÁ, 2014, p.3).

E ainda constará de atendimento em contraturno em sala de recurso multifuncional os alunos com as especificações:

Sala de Recursos Multifuncional (SRM) - DI (Deficiência Intelectual), DFN, TGD, TFE (Transtornos Funcionais Específicos (dislexia, hiperatividade, déficit de atenção).

Sala de Recursos Multifuncional (SRM) - Deficiência Visual;

Sala de Recursos Multifuncional (SRM) - Surdez;

Sala de Recursos Multifuncional (SRM) - AH/SD (Altas Habilidades e Superdotação); (PARANÁ, 2014, p. 4).

Sendo assim cabendo somente a estes alunos citados o Atendimento Educacional Especializado (AEE), que segundo a gestão escolar do governo do Paraná o define como:

É um conjunto de atividades, recursos pedagógicos e de acessibilidade, oferecidos de forma complementar ou suplementar à escolarização dos estudantes com deficiência, transtornos globais do desenvolvimento e altas habilidades/superdotação, matriculados nas classes comuns do ensino regular. O AEE deve estar contemplado no Projeto Político-Pedagógico de cada escola e pode ser realizado individualmente ou em pequenos grupos, no turno ou contraturno da escolarização. (Instrução no. 016/2011 - SEED/SUED, p. 2).

Dentro deste atendimento o aluno é assistido na sala de recursos multifuncional da mesma escola em que está matriculado na classe comum do ensino regular e também é definido pela gestão escolar do governo do Paraná o define como:

A SRM na Educação Básica é um atendimento educacional especializado (AEE), de natureza pedagógica, que complementa a escolarização de estudantes que apresentam deficiência intelectual, deficiência física neuromotora, transtornos globais do desenvolvimento e transtornos funcionais específicos, matriculados na rede pública de ensino. (INSTRUÇÃO № 016/2011 SEED/SUED, p. 1).

Mas existem outras deficiências, síndromes que também necessitariam de um profissional especializado para auxiliar em sala de aula e o mesmo não lhe é concedido por não fazer parte do rol das especificações acima citadas, como é o caso do sujeito da pesquisa aluno com da Síndrome de Noonan, evidenciado também na pesquisa de Moscardini (2011), onde destaca a problemática da inclusão 
e a situação de escolarização vivenciada por alunos matriculados em salas comuns e sala de recurso multifuncional (SRM).

A convivência entre pares diferentemente do cognitivo se torna prazerosa e com muito ganhos para ambos, segundo Monteiro e Castro (1997), alunos com deficiência, ao estarem inseridos numa sala de ensino regular, podem se desenvolver mais, dada a diversidade de modelos, do que quando só estão entre os alunos de iguais deficiências. Por outro lado, a convivência com os que são diferentes de si pode desenvolver um olhar de respeito e harmonia para aprender a conviver contra a violência.

\subsection{A perspectiva dos professores sobre a educação inclusiva}

Ao ser abordado sobre inclusão nas escolas, percebe-se nos professores bem como em Rozek ( 2010), que persistem dúvidas e incertezas quanto ao encaminhamento metodológico para a formação escolar do aluno, estas e outras objeções motivaram para a formação de um questionário que serviu de análise para delinear a perspectiva dos professores sobre a educação inclusiva. No desígnio de sistematizar as contribuições de ambos os campos, produção acadêmica e a posição dos professores, na busca de reconhcer formas efetivas de proporcionar uma educação inclusiva ativa e de qualidade.

Sempre que houver espaços para se discutir a inclusão no ambiente escolar a que se ponderar sobre questionamentos que servirão de reflexão aos próprios professores bem como toda a comunidade escolar a fim de encontrar respostas para melhor contribuir com o trabalho escolar para este aluno, entre elas, temos: Como os professores caracterizam a inclusão no ensino regular? Porque o aluno com uma determinada deficiência esta inserido na rede regular de ensino? É importante ressaltar assim como Maciel (2000) "que os professores tomem ciência do diagnóstico e do prognóstico do aluno com necessidades educativas especiais", isso quando as deficiências apresentadas pelo aluno não se encontra especificada pelo Anexo VII, (PARANÁ, 2014). Os professores possuem formação continua para desenvolver um trabalho mais efetivo com este aluno? Os professores dispõe de material e informação relevante para desempenhar e potencializar o ensino e por consequência a aprendizagem? Se essas questões foram levantadas nas escolas e não possuem respostas satisfatórias a quem se deve procurar? Sabe-se que o ensino deve ser igualitário, mas isto realmente tem se efetivado nas escolas 
regulares? (DIAS et all, 2015). Também questiona sobre as reais condições que se encontra a educação inclusiva segundo os professores.

Essas são incertezas das quais os professores do ensino regular deparam no cotidiano escolar. E que saibamos assim como Freire (2005) em sua obra Pedagogia da Autonomia que, devemos conviver com o diferente, assim como aponta Mantoan (2003) a necessidade de alunos diferentes ou não estarem convivendo num mesmo ambiente, numa mesma sala de ensino regular, é fundamental para o crescimento social e cognitivo do aluno, mesmo diante do todos os desafios e objeções.

Desde que os alunos de inclusão foram efetivamente aceito nas sala de aulas regulares tem se refletido muito sobre todos os aspectos que possa beneficia-los, mas o que se verifica, ainda, é a existência de inúmeros obstáculos, cabe ressaltar as lacunas presentes na comunicação entre professores e equipe pedagógica quando o referido é sobre alguma deficiência com diagnóstico novo, como é o contexto da Síndrome de Nooanm, que segundo a professora da SRM que acompanha o aluno, relata que: por ser uma síndrome nova na educação não se tem disponibilizado material para ser trabalhado de forma efetiva, tão pouco indicação de metodologia diferenciada, enquanto não existir estudos aprofundados, sempre com muita dedicação, os professores devem se organizar a fazer uma avaliação diagnóstica ${ }^{3}$ para a verificação do nível de entendimento do aluno, para assim saber quais materiais utilizar para uma melhor aplicabilidade favorecendo que ele consiga desenvolver a aprendizagem.

E assim agir com discernimento como aponta Zuffi (2014) onde "o professor deve ser sensível para analisar as condições intelectuais do estudante, independentemente da sua idade, para compreender o que é possível ser realizado e ampliar os ganhos no desenvolvimento da autonomia do aluno". Pois se assim, não o fizer recai na mesma fala da pesquisadora já mencionado anteriormente no perigo de se deixar o aluno ali solto e "perdido" entre tantos outros na sala, tudo em função de não saber conduzir tal situação.

\section{Material e métodos}

3

A avaliação diagnóstica é aquela realizada no início de um curso, período letivo ou unidade de ensino, com a intenção de constatar se os alunos apresentam ou não o domínio dos pré-requisitos necessários, isto é, se possuem os conhecimentos e habilidades imprescindíveis para as novas aprendizagens. É também utilizada para caracterizar eventuais problemas de aprendizagem e identificar suas possíveis causas, numa tentativa de saná-los. (HAYDT, 1988, p. 16-17). 
A pesquisa foi realizada em duas escolas públicas, sendo uma de ensino fundamental e outra de ensino fundamental e médio, ambas da rede estadual de Maringá - Paraná. As duas instituições escolhidas para a realização desta pesquisa seguiram alguns critérios, a saber, localização na zona urbana da cidade, ter espaço físico adequado para os alunos com necessidades educativas especiais e ter, no registro de matrícula da escola, alunos com necessidades educacionais especiais.

Dos profissionais que lecionavam nas duas escolas foi retirada uma pequena amostra para a realização da pesquisa, sendo estes professores atuantes no ano de 2018, lecionando para alunos com necessidades especiais ou não. Fez-se a coleta de dados através de questionários aplicados aos professores que se encaixavam no perfil da amostra da pesquisa. Foram no total de 21 professores, 16, lecionavam para o ensino fundamental e 5 lecionavam para o ensino médio.

O questionário utilizado nesta pesquisa continha vinte e duas perguntas objetivas e uma pergunta dissertativa, tendo como objetivando refletir sobre o trabalho do professor na educação inclusiva, a saber como eles: identificam a quais classificações pertence seus alunos de inclusão; como ocorre o trabalho da inclusão nas salas de aulas comum, estão sendo orientando a trabalhar com esses alunos, como é a relação de convivência entre os alunos da sala e os de inclusão, se desenvolvem um trabalho diferenciado com estes alunos, se aplicam avaliações diferenciadas e pertinentes aos alunos de inclusão, se participam de formação continuada, se lhes são disponibilizados materiais diferenciados para trabalhar e se tem conhecimento da síndrome do indivíduo da pesquisa.

\section{Resultados e discussão}

Os questionários foram apresentados aos professores aleatoriamente, no horário de sua hora atividade, onde cada professor o respondeu individualmente, não trocando informações com os colegas.

Os resultados após análises apontam que são professores com uma vasta caminhada curricular, cerca de $33,3 \%$ possuem entre 11 a 15 anos de experiências, em sua maioria mulheres, todas com especialização, a amostra foi composta de 16 professores trabalhando no ensino fundamental e 5 professores no ensino médio, de diversas disciplinas, $61,9 \%$ desta amostra trabalha com alunos de inclusão a mais de 6 anos, e já tiveram as mais variadas classificações de deficiências tais como é mostrado no gráfico 1 , retirado do questionário: 


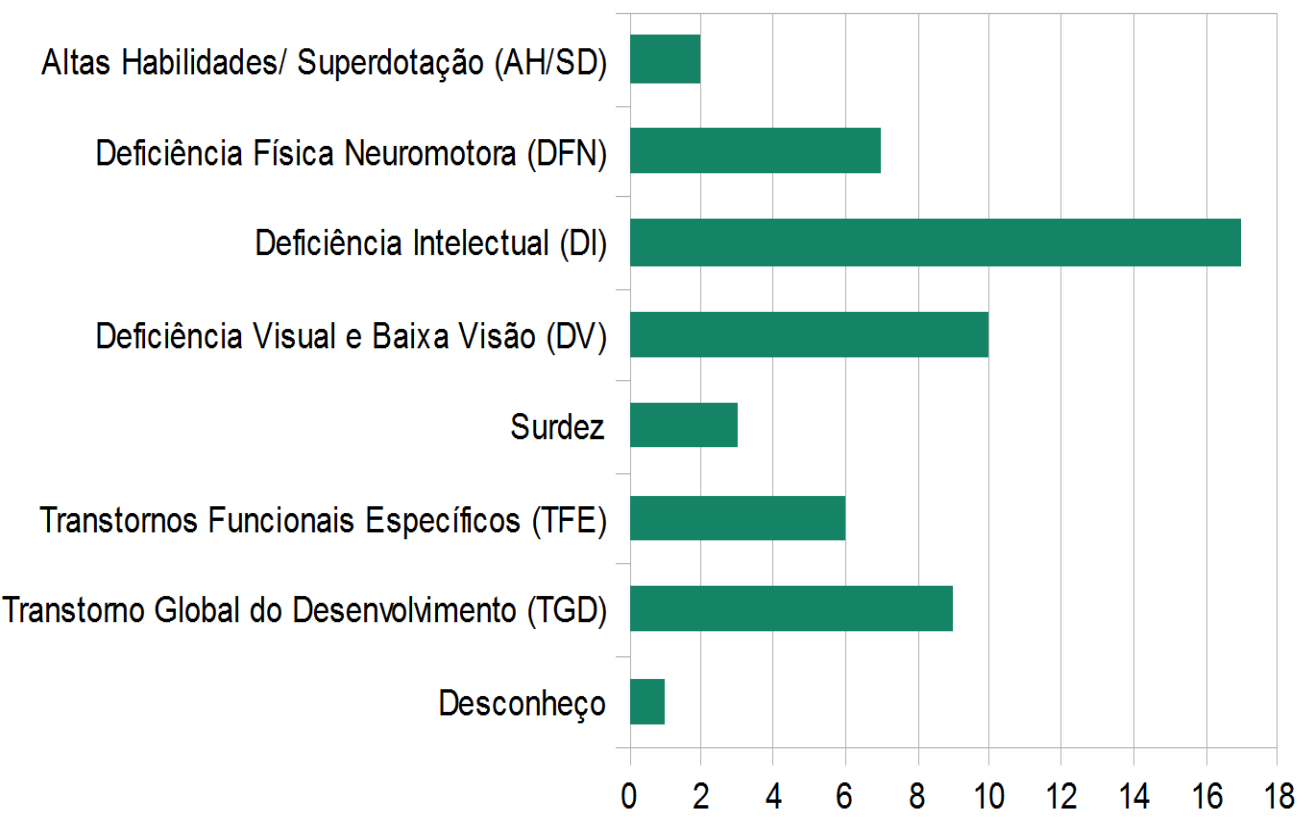

Gráfico 1: Questão 8: Seu aluno de inclusão pertence a qual(is) desta(s) classificação(ões)?

Fonte: Questionário (2018)

Ao analisar as primeiras questões percebe-se assim como Valle e Guedes (2003), que os professores não precisam ter conhecimento de todas as deficiências, mas estar em constante formação para saber colaborar com estes alunos proporcionando um ensino de qualidade.

Os professores relataram que após, a implementação da inclusão em sala aula, houve a necessidade de alteração de seu plano de trabalho docente para ministrar as aulas, dos quais $81 \%$ afirmaram realizar tal mudança, Figueiredo (2008) comenta da dificuldade de se desenvolver um bom trabalho, de educação igualitária o que também é identificado nas afirmações dos professores, evidenciando que não é uma tarefa fácil, visto assim como a autora, que comenta da discriminação que deve ser evitada cuidadosamente pelos professores. Em relação aos alunos, os professores comentaram que existe um alto índice de refutação quanto ao diferente, em torno de $66,7 \%$ identificaram preconceito na aceitação dos alunos de inclusão.

Em relação as orientações escolares ao professor sobre como desempenhálas com esses alunos 57, 1\% dos entrevistados afirmam que tiveram, mas $71,4 \%$ deste mesmos professores apesar de receber orientações alegam que a escola não tem material necessário para se trabalhar adequadamente com estes alunos, como também evidenciado Silva e Arruda ( 2014), quando também comentam que as as escolas não oferecem subsídios para se trabalhar com esses alunos e suas limitações. (SILVA \& ARRUDA, 2014, p. 1). 
Contudo as adversidades só tendem a aumentar, como apontam os professores onde, 90,5\% destes relatam sentir dificuldades em trabalhar com estes alunos, mesmo sabendo que essa inclusão é favorável de alguma forma para este aluno, como apontam Mantoan (2003), o relato do professor A traduz como a inclusão é analisada por ele: Professor A: A prática inclusiva só contribui no sentido da socialização, porque no aprendizado o aluno fica prejudicado.

Ainda constata-se na pesquisa que $71,4 \%$ dos professores têm dificuldade em se comunicar com o aluno, e 61,9\%, dos professores argumentaram que a interação também entre os alunos é comprometida, nos relatos dos professores observa-se que existe uma forte rejeição por parte dos alunos menores,com faixa etária de 11 a 13 anos, que se econtram matriculados nos $6^{\circ}$ e $7^{\circ}$ anos e principalmente, se não foram de mesma sala em anos anteriores, tudo é mais complexo, não há vinculo, para isso a intervenção do professor é importantíssimo para que seja harmonia em sala, assim como determina o MEC, SEESP:

A integração é um processo dinâmico de participação das pessoas num contexto relacional, legitimando sua interação nos grupos sociais. A integração implica em reciprocidade. E sob o enfoque escolar processo gradual e dinâmico que pode tomar distintas formas de acordo com as necessidades e habilidades dos alunos. Sob o enfoque psicossocial, a integração representa, portanto, numa via de mão dupla, envolvendo os portadores de deficiência e a comunidade das pessoas consideradas "normais" (1SEESP, 994, p.18).

Diante desta realidade e ao serem questionado se desenvolvem práticas diferenciadas com o aluno de inclusão, as opiniões se divergem, como se pode observar no gráfico 2, o que neste momento nos faz refletir que diante a diversos obstáculos apontados pelos professores anteriormente, muitos ainda não conseguem desempenhar ações e não conseguem assim sentir-se aptos a efetivar a inclusão com qualidade como proferida, onde as necessidades deveriam ter um olhar individualizado como aponta Silva e Arruda (2014) :

avaliar alunos com necessidades especiais, verificando o grau de dificuldade de cada um em sala de aula, descobrindo habilidades e potencialidades que precisam ser exploradas e modificadas de ambas as partes, capacitando melhor o profissional. (SILVA \& ARRUDA, 2014, p. 2).

Gráfico 2: Questão 17: Você desenvolve um trabalho diferenciado com o aluno de inclusão? 


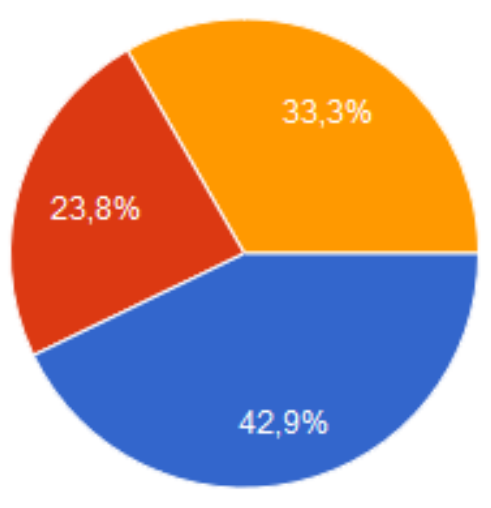

Fonte: Questionário (2018)

Da mesma forma quando questionado se ocorre uma avaliação forma distinta e diferenciada, o resultado se mostrou bem distante do que deveria ser a real inclusão, se este professor não se encontrar preparado a desenvolver práticas diferenciadas sua avaliação também será nos moldes para os mesmos alunos da sala de aula comum, como nos mostra no gráfico 3 .

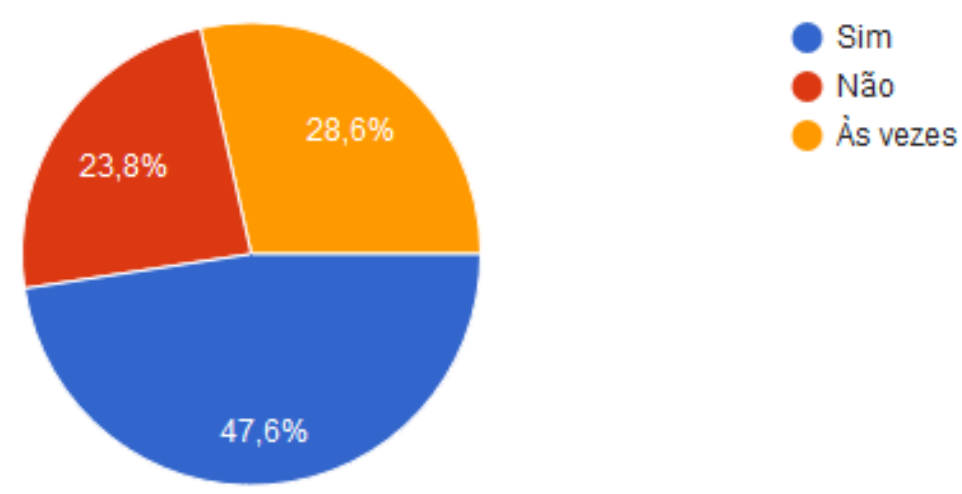

Gráfico 3: Questão 18: Você avalia o aluno de inclusão de forma diferenciada?

Fonte: Questionário (2018)

Para se avaliar diferenciado, o evoluir de toda a aula também deve ser diferenciado, mas analisando os dois gráficos anteriores, percebe-se como se apresentam de forma similar e uma ação é reflexo da outra, se menos de $50 \%$ dos professores desenvolvem ações diferenciadas, assim também será o comportamento quanto as avaliações. Deve-se destacar, ainda, que necessita-se de formações, preparações, respaldo educacional para poder avançar nesta situação, 
visto que a cada ano letivo está mais crescente o número de alunos inclusos nas escolas regulares como visto anteriormente e se a prática profissional permanecer a mesma, pouco se muda para este aluno, (DENARI, 2001), também faz uma reflexão sobre essas práticas, a qual julga ser pertinente o dialogo entre todos os envolvidos, comunidades escolar, família, para o bom desenvolvimento cognitivo do aluno.

E considerando esta viés ao ser perguntado sobre a utilização de algum recurso didático/pedagógico específico para integrar o aluno incluso com os alunos comuns, pelo comparativo das análises anteriores destaca-se que o trabalho fica a desejar, em relação a inclusão o que corrobora com o gráfico 4:

Gráfico 4: Questão 20: Você utiliza algum recurso didático/pedagógico específico para integrar o aluno incluso com os alunos comuns.

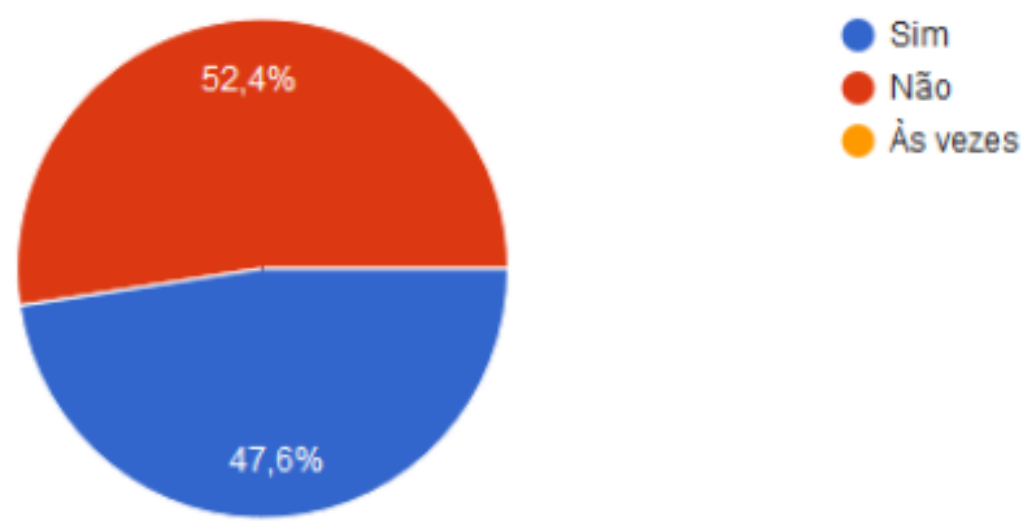

Fonte: Questionário (2018)

Pelo gráfico, pode-se constatar que os professores não utilizam recurso didático/pedagógico específico da forma como deveria ser feito, pois mais da metade dos professores o que equivale a $52,4 \%$, não o fazem, o que compromete todo o trabalho dos $47,6 \%$ professores que procuram diferenciar, seu atendimento ao aluno de inclusão, uma realidade, distante do esperado logo não se terá um ensino diferenciado respeitando as limitações do aluno, bem como comentam Rodrigues (2003) e Roldão (2003), sobre os professores que ainda trabalham de forma tradicional, e não consideram importante seu aluno de inclusão.

Diante dos eventos até o momento apresentado, a escola não pode omitir o que ocorre ao seu redor, tão pouco anular e segregar as desigualdades nos processos pelas quais forma se instrui os alunos, igualmente indicando por (MANTOAN 2003, p. 12), infelizmente por diversas razões a inclusão ainda precisa 
ser melhor direcionada e ao ser perguntados os motivos pelos quais a inclusão ainda é algo a ser revisto e repensado em sala de aula, os professores indicaram alguns fatores:

A falta de formação continuada e material pedagógico foi o obstáculo mais apontado pelos professores, seguido da falta de tempo para a preparação para o atendimento a estes alunos, há muito ainda o que se melhorar, muitos ainda argumentaram outros fatores também importantes a serem discutidos para se manifestar e levar em consideração o porque ainda a inclusão se torna deficitária, assim como já foi muito discutida e referendada por diversos autores como também relembra Goffredo (1992) e Manzini (1999) sobre as limitações e dificuldades em todos os aspectos que a escola enfrenta ao se referir a inclusão, na sequência os professores relataram outras evidências das dificuldades encontradas, onde estes serão identificados por letras:

Prof. B: Na disciplina de Ciências, os conteúdos são muitos diversos são necessários adequações para cada situação por vez, além de ser uma disciplina experimental, também se faz necessário um maior suporte de materiais, laboratório, espaço físico e recursos humanos.

Prof. C: O número de alunos em sala, quando há alunos inclusos deveria ser reduzido, o que raramente acontece; consequentemente o prejuízo para o aluno é imensurável assim como, a angustia do professor por não dar a atenção necessária ao mesmo.

Prof. D: Os alunos inclusos necessitam de maior atenção o que dispensa maior dedicação e tempo do professor. Outra dificuldade é que cada aluno incluso tem uma especificidade que às vezes carece de maior intercambio com 0 especialista que o atende fora da sala de aula.

Prof. E: A minha dificuldade em atender os alunos de inclusão é saber lidar com vários problemas cognitivos diferentes na mesma sala de aula.

Prof. F: De primeiro momento há necessidade de investigar quais conhecimentos os alunos dominam, e a partir daí fazer as intervenções para apresentar novos conhecimentos. A principal dificuldade é a falta de um trabalho coletivo (professor da sala regular, professor de apoio, família, equipe pedagógica).

Percebe-se que os professores aspiram o entendimento de como proceder em relação às dificuldades e potencialidades apresentadas diante aos fato, porém as limitações são muitas, almejam contribuir, mas os obstáculos são proeminentes o que impossibilita a cada tentativa de cooperação, embora a busca por formações individuais ocorra, Prieto (2006), argumenta que este é o caminho para a educação 
de qualidade,

A formação continuada do professor deve ser um compromisso dos sistemas de ensino comprometidos com qualidade do ensino que, nessa perspectiva, devem assegurar que sejam aptos a elaborar e a implantar novas propostas e práticas de ensino para responder às características de seus alunos, incluindo aquelas evidenciadas pelos alunos com necessidades educacionais.(PRIETO,2006, p.57).

E em relação a Síndrome de Noonan, quando questionado, os próprios professores que tem este aluno em sala de aula, disseram desconhecer a síndrome, algumas hipóteses foram levantadas, seja por ser nova, por estes não ter conhecimentos das dificuldades que apresentaria cognitivamente o aluno e assim não se ter material para desempenhar praticas efetivas com o mesmo, ou até porque a escola apresentou o aluno como deficiente intelectual, o que deixa os professores numa zona de conforto mais agradável, segundo professor $\mathrm{C}$ : não sei trabalhar com a SN, mas sei como desenvolver e trabalhar com o aluno com deficiência intelectual.

Alguns autores como Dias (2004), apontam em sua pesquisa que existem uma quantidade pequena de material publicado sobre $\mathrm{SN}$, identificou que o mesmo se refere a deficiência intelectual e não há investigações específicas a respeito de outras funções cognitivas, para Malaquias et al. (2008), existem graus de atraso no desenvolvimento neuropsicomotor e em alguns casos dificuldade de aprendizagem o que exige acompanhamento especial. Entretanto, a maioria dos indivíduos com SN (85\%) apresentam boa qualidade de vida e integração social, para Padovani (2011) o prejuízo é significativo quanto à classificação e registros, mas ainda são sutis as pesquisas realizadas sobre a síndrome.

E em números em torno de, 66,7\% dos professores disseram desconhecer a síndrome e 23,8\% disseram não ter aluno com esta síndrome, somente 9,5\% deste, o que corresponde a 2 professores disseram ter conhecimento do aluno em sala com SN, além de todos os problemas levantados pelos professores, ainda falta comunicação entre equipe pedagógica, família e professores para se realizar um ensino de qualidade com o aluno de inclusão, assim como menciona. Alves (2009) quando relata que para uma educação inclusiva mais efetiva:

o importante não é só capacitar o professor, mas também toda equipe de funcionários desta escola, já que o indivíduo não estará apenas dentro de sala de aula. [...] Alguém tem por obrigação treinar estes profissionais. Não adiante cobrar sem dar subsídios suficientes para uma boa adaptação deste indivíduo na escola. Esta preparação, 
com todos os profissionais serve para promover o progresso no sentido do estabelecimento de escolas inclusivas (ALVES, 2009, p.45,46).

Muito já se refletiu, a inclusão já faz parte da realidade das escolas comuns, mas os problemas que os acercam ainda são os mesmos, mudanças devem existir, deve-se mobilizar toda a comunidade escolar para promover a igualdade da inclusão social.

\section{Considerações Finais}

Ao se falar em necessidades especiais não se diz respeito apenas a alunos que são o público-alvo do AEE (Atendimento Educacional Especializado), conforme estão descritos no Anexo VII - Organização do trabalho pedagógico especializado na rede pública estadual de ensino de 2014 (PARANÁ, 2014, p.3), mas sim todo sujeito que possui alguma deficiência da qual não encontra categorizado neste Anexo VII, como é o aluno com SN, que não se enquadra em nenhuma das especificações, porém é tratado como deficiente intelectual, por não se ter conhecimento necessário de como desenvolver um trabalho diferenciado com este indivíduo, os professores se veem desafiados a concretizar suas ações em elaborar atividades que julgam ser apropriadas para o seu grau de compreensão.

Portanto seria de suma importância que cada síndrome fosse apresentado seu diagnóstico para assim traçar o melhor encaminhamento pedagógico para 0 aluno, respeitando suas necessidades e especificidade, e não estivesse somente sendo atendidas as categorias citadas no Anexo VII.

Desta forma proporcionaria que a comunidade escolar pudesse desenvolver um trabalho igualitário, com uma comunicação linear entre família e escola, com atendimento específico a um número de contingente de síndromes presentes nas escolas regulares, com maior preparação, formação continuada e materiais de apoio.

Mas, o que aponta pelo relato dos professores e pela própria pesquisa é uma carência extrema, uma insegurança no qual o aluno a todo momento requer atenção principalmente no caso do aluno com SN, que também deseja ensinamentos e o único a auxiliar é o professor regente da sala regular, o que torna desgastante, inviável e gerando uma neglicência quanto a inclusão, pelos problemas que gera ao se dedicar atenção exclusiva a este aluno por um tempo maior em aula. E que os 
professores ainda não estão preparados a trabalharem com a inclusão nas salas de aula, principalmente com as síndromes que há falta estudos, como é a SN.

Estamos vivendo na contramão da inclusão, por diversas razões aqui já mencionada, mas há a necessidade de buscar soluções pois a inclusão é uma realidade que a cada dia está mais presente nas escolas comuns, e não se pode negar o direito desde aluno esta inserido e fazer parte desde ambiente escolar, como diz Mantoan (2003), a educação escolar deve ser pensada a partir da integração do aluno, de acordo suas capacidades e talentos, proporcionando ao aluno para que seu ambiente escolar seja de forma participativa, acolhedora e solidária. E para que isso aconteça se faz necessário o exercício diário de cooperação, de fraternidade, do reconhecimento e do valor das diferenças.

\section{Referências}

ALVES, Fátima. Inclusão: muitos olhares, vários caminhos e um grande desafio. Rio de Janeiro, WAK EDITORA, 2009.

BERTOLA, Débora Romeo. Contribuição para o estudo clínico e genético da síndrome de Noonan. [dissertação]. São Paulo: Faculdade de Medicina da Universidade de São Paulo; 1999. 251 p.

BERTOLA, Débora Romeo. Estudo do gene PTNP11 nos pacientes afetados pela síndrome de Noonan; Tese (Doutorado em Pediatria) -Faculdade de Medicina da Universidade de São Paulo. São Paulo, 2006.

BRASIL. Declaração de Salamanca e linha de ação sobre necessidades educativas especiais. Brasília: UNESCO, 1994.

BRASIL. Ministério da Educação e Cultura. Secretaria de Educação Especial Política Nacional de Educação Especial. Brasília:, MEC/SEESP 1994.

BRASIL. Ministério da Educação. Secretaria de Educação Especial. Política Nacional de Educação Especial na Perspectiva da Educação Inclusiva. Brasília:, 2007.

BRASIL, Amanda Salem. Estudo dos genes PTNP11 e KRAS em pacientes afetados pela síndrome de Noonan e pelas síndromes Noonan-like.

[dissertação]. São Paulo: Faculdade de Medicina da Universidade de São Paulo; 2009. $94 \mathrm{p}$.

BRASIL. Lei no 13146, de 6 de julho de 2015. Institui a Lei Brasileira de Inclusão da Pessoa com Deficiência (Estatuto da Pessoa com Deficiência). Brasília: Câmara dos Deputados, Edições Câmara, 2015. - (Série legislação; n. 216). 
deficiência na escola regular numa região do município de São Paulo: conhecendo 428 estratégias e ações. Rev. bras. educ. espec. [online]. 2012, vol.18, n.1, pp. 141-154. ISSN 1413-6538

DENARI, Fátima Elisabeth. A Escola Perante as Diferenças: Um Olhar sobre a Formação do Professor. In: MARQUEZINE, M. C.; ALMEIDA, M. A.; TANAKA, E. D. (Orgs.). Perspectivas Multidisciplinares em Educação Especial II. Londrina: Editora UEL, 2001, p. 177-182.

DIAS, Marian Ávila de Lima e; ROSA, Simone Conceição \& ANDRADE, Patrícia Ferreira. Os professores e a educação inclusiva: identificação dos fatores necessários à sua implementação. Psicol. USP [online]. 2015, vol.26, n.3, pp.453463. ISSN 0103-6564. http://dx.doi.org/10.1590/0103-656420140017.

DIAS, Vanderson Glerian et al. Síndrome de Noonan: relato de caso. Arq. Bras. Oftalmol., vol.67, no.4, p.665-667. 2004.

DRAGO, Rogério, PINEL, Hiran. Alunos com síndrome rara na escola comum: um olhar fenomenológico-existencial. Linhas Críticas [en linea] 2014, 20 (Septiembre-Diciembre): Disponível em: $\leq$ http://www.redalyc.org/articulo.oa?id=193532896007>ISSN 1516-4896. Acesso em: 03 de março de 2019.

FERREIRA, Denize Cristina Kaminski. Salas de Atendimento Educacional Especializado (AEE) na rede regular pública de ensino paranaense: desafios, limites e possibilidades do paradigma inclusivo. Revista de Educação Especial, v. 29 , n. 55 , p. 281-294, 2016.

FREIRE, Paulo. Pedagogia da autonomia: saberes necessários à prática educativa. 13. ed. São Paulo: Paz e Terra, 2005.

FIGUEIREDO, Rita Vieira. A formação de professores para inclusão dos alunos no espaço pedagógico da diversidade. In: Maria Tereza Eglér Mantoan. (Org.). O desafio das diferenças nas escolas. 1 ed. Petrópolis: Vozes, 2008, v. 1, p. 141-145.

GLAT, Rosana; PLETSCH, Márcia Denise. O método de história de vida em pesquisas sobre auto-percepção de pessoas com necessidades educacionais especiais. Revista Educação Especial, UFMA v. 22, n. 34, p. 139-154, 2009.

GOFFREDO, V. Integração ou segregação? O discurso e a prática das escolas públicas da rede oficial do município do Rio de Janeiro. Integração, v. 4, n. 10, p. 118-127, 1992.

HAYDT, Regina Célia Cazaux. Avaliação do processo ensino-aprendizagem.São Paulo: Ática, 1988.

JESUS, Denise Meyrelles de; EFFGEN, Adriana Pereira Siqueira: Formação docente e práticas pedagógicas: Conexões, possibilidades e tensões.IN: MIRANDA, Therezinha Guimarães; FILHO. Teófilo Alves Galvão (ORGS): Formação, práticas e lugares. Salvador: EDUFBA, 2012. 
KOBYLINSK, Oskar. Ueber eine flughautahnliche Ausbreitung am Halse. Arch Anthrop. 1883; 14: 343-348.

KUZUYABU, Marina. Dificuldade da inclusão divide professores e especialistas. Revista Educação, São Paulo, ano 19, no 228, p. 32-37, abril/2016.

MALAQUIAS, Alexsandra Christianne. Síndrome de Noonan: do fenótipo à terapêutica com hormônio de crescimento. Disponível em:

$<$ http://www.producao.usp.br/bitstream/handle/BDPI/8893/art MALAQUIAS Sindrom $\underline{\mathrm{e}}$ de Noonan do fenotipo a terapeutica 2008.pdf? sequence $=1$ \&isAllowed $=\mathrm{y}>$. Acesso em: 15 abr. 2018.

MANTOAN, Maria Tereza Eglér. Inclusão Escolar:o que é? por quê? como fazer? São Paulo: Moderna, 2003.

MANZINI, E. F. Quais as expectativas com relação à inclusão escolar do ponto de vista do educador? Temas sobre desenvolvimento, v. 7, n. 42, p. 52-54, 1999.

MEDINA, Vilma. A Síndrome de Noonan nas crianças. Guiainfantil.com. 2018. Disponível em: https://br.guiainfantil.com/materias/saudea-sindrome-de-noonan-nascriancas/. Acesso em: 19 ago. 2018.

MENDEZ, H. M.; OPITZ, J.M., REYNOLDS, J. F. Am. J. Med Genet, v. 21, p. 493506. 1985.

MONTEIRO, Maria. Benedicta; CASTRO, Paula. Cada cabeça sua sentença. Oeira: Celta, 1997.

MOSCARDINI, Saulo Fantato. Escolarização de alunos com deficiência intelectual em classes comuns e em salas de recursos multifuncionais. 2011. 194 f. Dissertação (mestrado) - Universidade Estadual Paulista, Faculdade de Ciências e Letras de Araraquara, 2011.

MOTA, Érica Regina et al. Alterações comportamentais na Síndrome de Noonan: dados preliminares brasileiros. rev.latinoam.psicol., Jan 2010, vol.42, no.1, p.8795.

NOONAN, Jacqueline; EHMKE DA - Associated noncardiac malformations in children with congenital heart disease. J Pediatr 1963; 63: 468-470.

NORA, JJ; NORA AH; SINHA AK; SPANGLER,RD; LUBS, HA.The Ullrich-Noonan syndrome (Turner phenotype).Am J Dis Child. 1974 Jan;127(1):48-55.

OPTIZ, JM. Noonan's syndrome in girls: a genecopy, of the Ullrich-Turner syndrome. J pediatr, 1965, 67989.

OLIVEIRA, Anna Augusta Sampaio de; LEITE, Lucia Pereira. Construção de um sistema educacional inclusivo: um desafio político-pedagógico. Revista Ensaio: 
Avaliação e Políticas Públicas em Educação. Vol. 15, fascículo 57, Cesgranrio/RJ, 2007.

PADOVANI, Carolina Rabello. Perfil cognitivo de pessoas portadoras da síndrome de Noonan com mutação no gene PTPN11. [dissertação]. São Paulo: Universidade de São Paulo; 2011. 100 p.

PARANÁ, Departamento de Educação de Educação Especial do estado do, INCLUSÃO E DIVERSIDADE: REFLEXÕES PARA A CONSTRUÇÃO DO PROJETO POLÍTICO PEDAGÓGICO, Disponivel em: http://www.gestaoescolar.diaadia.pr.gov.br/arquivos/File/sem pedagogica/fev 2010/i nclusao diversidade.pdf, Acesso em: 21 jan. 2019.

PARANÁ, Gestão Escolar do estado do. FAQ - Perguntas frequentes - Educação Especial - Atendimento Educacional Especializado (AEE). Disponível em: http://www.gestaoescolar.diaadia.pr.gov.br/modules/faq/category.php?categoryid=96. Acesso em: 29 abr. 2018.

PARANÁ. Secretaria de Estado da Educação do. CENSO ESCOLAR DA EDUCAÇÃO BÁSICA - 2000-2017 MATRÍCULA INICIAL - PARANÁ. Disponível em:

http://www.gestaoescolar.diaadia.pr.gov.br/arquivos/File/censo/serie historica matric ula inicial2000 2017.pdf. Acesso em: 31 mai. 2018.

PARANÁ. Secretaria de Estado da Educação do, Superintendência da Educação. INSTRUÇÃO №. 016/2011 SEED/SUED. Meroujy Giacomassi Cavet Superintendente da Educação. Curitiba 22 de novembro de 2011.

PARANÁ. Secretaria de Estado da Educação do. Orientações para a Organização da Semana Pedagógica, Anexo VII, julho 2014.. Disponível em: http://www.gestaoescolar.diaadia.pr.gov.br/arquivos/File/sem pedagogica/julho 2014 lanexo7.pdf, Acesso em: 10 nov. 2018.

PRIETO, Rosângela Gavioli. Atendimento escolar de alunos com necessidades educacionais: um olhar sobre as políticas públicas de educação no Brasil. In: ARANTES, Valéria Amorim. (Org.). Inclusão escolar: pontos e contrapontos. São Paulo: Ed. Summus, 2006. p. $31-74$.

RODRIGUES, D. "Educação Inclusiva: as boas e as más notícias", in: David Rodrigues (Org.) "Perspectivas sobre a Inclusão; da Educação à Sociedade", Porto Editora, Porto. 2003.

ROLDÃO, Maria do Céu. "Diferenciação Curricular e Inclusão", in: David Rodrigues (Org.) "Perspectivas sobre a Inclusão; da Educação à Sociedade",Porto Editora, Porto. 2003.

ROZEK, Marlene. Subjetividade, formação e educação especial: histórias de vida de professoras. Tese de Doutorado em Educação. Programa de PósGraduação da Universidade Federal do Rio Grande do Sul; Porto Alegre,2010. 
SHARLAND, M; BURCH, M; MCKENNA, W. M; PATTON, M. A. A Clinical Study of Noonan Syndrome. Arch Dis Child, v. 67, p. 178-183, 1992.

SILVA, Ana Paula Mesquitada; ARRUDA, Aparecida Luvizotto Medina Martins.o Papel do Professor Diante da Inclusão Escolar. Revista Eletrônica Saberes da Educação - Volume 5 - no 1-2014.

SIQUEIRA. Gisele Nunes. Educação inclusiva: desafios docentes da inclusão nas escolas municipais de Formosa-GO. 2015 53f. TCC (Graduação- Licencitura em Ciências Biológicas) - Instituto Federal de Educação, Ciências e Tecnologia de Goiás, Formosa, 2015.

TARTAGLIA, M.; MEHLER, E. L.; GOLDBERG, R.; ZAMPINO, G; BRUNNER, H. G.; KREMER, H.; VAN DER BURGT, I; CROSBY, A. H.; ION, A.; JEFFREY, S.;

KALIDAS, K.; PATTON, M. A.; KUCHERLAPATI, R. S.; GELB, B. D. Mutations in PTPN11, encoding the protein tyrosine phosphatase SHP-2, cause Noonan Syndrome. Nat Genet, v. 29 p. 465-468. 2001.

VALLE, Maria Helena Feres. GUEDES, Teresinha Ribeiro. Habilidades e competências do professor frente à inclusão. In: SOBRINHO, Francisco de Paula NUNES. (Org.). Inclusão Educacional: Pesquisa e Interfaces. Rio de Janeiro: Livre Expressão, 2003, p. $42-61$.

ZUFFI, Edna., Novos métodos transformam ensino de matemática para alunos com deficiência. Educação e Ciência, 2014. Disponível em $<$ http://www.brasil.gov.br/editoria/educacao-e-ciencia/2014/12/novos-metodostransformam-ensino-de-matematica-para-alunos-com-deficiencia>. Acesso em: 26 mai. 2018. 